Check for updates

Cite this: RSC Adv., 2019, 9, 26542

Received 31st July 2019

Accepted 16th August 2019

DOI: $10.1039 / c 9 r a 05947 d$

rsc.li/rsc-advances

\section{Functionalized polycarbonates via triphenylborane catalyzed polymerization-hydrosilylation $\uparrow$}

\author{
Kori A. Andrea (D) and Francesca M. Kerton (D) *
}

Triphenylborane catalyzes the copolymerization and terpolymerization of epoxides and $\mathrm{CO}_{2}$ to yield polycarbonates with excellent dispersity. Via assisted tandem catalysis, these materials could be hydrosilylated in a one-pot fashion yielding modified polymeric materials. Using only a few reagents, materials with glass transition temperatures ranging from $37-110^{\circ} \mathrm{C}$ were obtained.
Transformation of carbon dioxide $\left(\mathrm{CO}_{2}\right)$ into useful organic materials is important from an economic and environmental viewpoint. ${ }^{1,2}$ Specifically, the reaction of $\mathrm{CO}_{2}$ and epoxides can yield either cyclic carbonates or polycarbonates, with product selectivity relying on several factors such as temperature, pressure, substrate and catalyst design. The polycarbonate product is attractive as it paves a new road towards the development of new sustainable polymeric materials that may serve as alternatives to the traditional petroleum-based products that dominate society today. ${ }^{3-5}$ The use of catalysts that can incorporate a mixture of epoxide monomers into the final product has evolved in recent years, which can allow renewable functional epoxides to be incorporated into a biorenewable end product. ${ }^{6,7}$ Furthermore, such functional epoxides including unsaturated building blocks allow for subsequent modification and tailoring of the polymer and its properties. This has been achieved previously, ${ }^{8}$ for example, via olefin metathesis and thiol-ene crosslinking reactions. ${ }^{8-14}$

Copolymerization of epoxides and $\mathrm{CO}_{2}$ is usually facilitated by metal-based catalytic systems, ${ }^{6,15}$ but recently the use of organo- and non-metal catalysts has emerged, ${ }^{16}$ including two examples making use of organoboranes. The first used triethylborane to yield polycarbonates with high carbonate content when either propylene oxide (PO) or cyclohexene oxide (CHO) were used as the substrate. ${ }^{17}$ We recently reported the use of arylboranes, both triphenylborane $\left(\mathrm{BPh}_{3}\right)$ and the more Lewis acidic tris(pentafluorophenyl)borane (BCF), as catalysts for the production of either cyclic carbonate or polycarbonate products with substrate dependent selectivity. ${ }^{18}$

Triarylboranes, particularly BCF, either alone or as a Frustrated Lewis Pair (FLP) or within a complex ion-pair are known to catalyze a broad range of reactions, ${ }^{19-24}$ including hydroelementations that possess enormous potential for production of chemicals in a sustainable manner. ${ }^{25,26}$

Department of Chemistry, Memorial University of Newfoundland, St. John's, NL A1B 3X7, Canada.E-mail: fkerton@mun.ca

$\dagger$ Electronic supplementary information (ESI) available: Detailed information on experimental procedures and characterization data. See DOI: 10.1039/c9ra05947d
Specifically, hydrosilylation involves the addition of $\mathrm{Si}-\mathrm{H}$ groups across $\mathrm{C}-\mathrm{C}, \mathrm{C}-\mathrm{O}$ and $\mathrm{C}-\mathrm{N}$ multiple bonds. ${ }^{27}$ As hydrosilylation of alkenes by BCF had been reported, ${ }^{21}$ along with our recent report of $\mathrm{BPh}_{3}$ catalyzed copolymerization of $\mathrm{CO}_{2}$ and vinylcyclohexene oxide (VCHO), we were motivated to combine these two reactions in one-pot to yield silylatedpolycarbonates. Herein, we report the first example of an alkene hydrosilylation catalyzed by the less Lewis acidic $\mathrm{BPh}_{3}$. Building on our previous findings regarding the ability of $\mathrm{BPh}_{3}$ to produce perfectly alternating polycarbonates, we report sequential copolymerization-hydrosilylation in a onepot manner via assisted tandem catalysis (Scheme 1). We anticipate that such processes can lead to $\mathrm{CO}_{2}$-derived polymers with tailorable physical properties including glass transition temperatures. Also, these polymers may show enhanced solubility in organic solvents, which will facilitate film-casting, and if some $\mathrm{Si}-\mathrm{H}$ bonds remain, it may allow polymers to be attached to surfaces via covalent bonding or grafted to other macromolecular species to form more complex architectures.

The vinyl groups of the polyvinylcyclohexene carbonate (PVCHC) provide several potential routes to polymer modification, which could result in tuning of its physical and chemical properties. This has been done previously using methods such

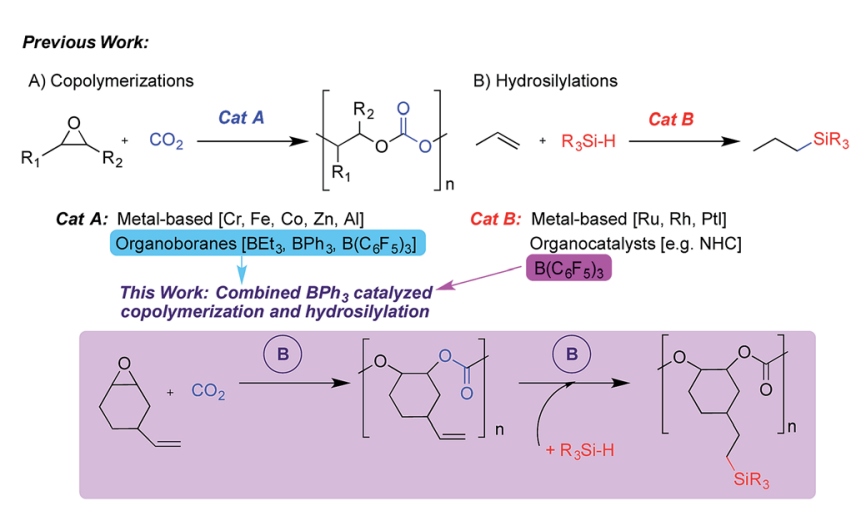

Scheme 1 Catalytic copolymerization and hydrosilylation. 
as thiol-ene click chemistry ${ }^{28}$ and metathesis. ${ }^{10,18}$ BCF is known to activate $\mathrm{Si}-\mathrm{H}$ bonds and facilitate their addition across unsaturated substrates, ${ }^{\mathbf{2 1 , 2 9 , 3 0}}$ whereas $\mathrm{BPh}_{3}$ has been studied to a lesser extent. We envisioned that $\mathrm{BPh}_{3}$ would be able to catalyze the addition of $\mathrm{Si}-\mathrm{H}$ groups onto a vinyl-substituted polycarbonate. Therefore, we performed the following 'onepot' sequence (Fig. 1): $\mathrm{BPh}_{3}$ was used to catalyze the copolymerization of VCHO and $\mathrm{CO}_{2}$, the $\mathrm{CO}_{2}$ was vented and phenyldimethylsilane added to the reaction mixture so the $\mathrm{BPh}_{3}$ present could then catalyze the hydrosilylation of the alkene within the polycarbonate. We did not attempt to perform the hydrosilylation reaction in the presence of $\mathrm{CO}_{2}$, or prior to or during the copolymerization, as $\mathrm{BPh}_{3}$ is able to hydrosilylate $\mathrm{CO}_{2}$ but does not react with propylene carbonate, ${ }^{31}$ and we presume other carbonates. We monitored the one-pot process via in situ IR spectroscopy. The formation of PVCHC was monitored via growth of the carbonate stretch at $1747 \mathrm{~cm}^{-1}$. We observed no induction period and signal saturation occurred within approximately $1 \mathrm{~h}$. After $24 \mathrm{~h}$, we cooled and depressurized the vessel before injecting a mixture of phenyldimethylsilane in dichloromethane and heating to $40{ }^{\circ} \mathrm{C}$. A trial hydrosilylation reaction (NMR scale) on isolated PVCHC was successful at this temperature. However, for the one pot process after 4 days, no new bands were observed in the IR spectrum. Upon increasing the temperature to $60{ }^{\circ} \mathrm{C}$, within hours we saw a decrease in intensity of bands at 2122 and $882 \mathrm{~cm}^{-1}$ $\left(\mathrm{PhMe}_{2} \mathrm{SiH}\right)$, and an increase in intensity of bands at 834 and $791 \mathrm{~cm}^{-1}$ demonstrating the successful addition of the silane across the alkene of the polycarbonate. The higher temperature for the one-pot process is likely needed to displace the $\mathrm{Cl}^{-}$ anion from the boron centre and allow activation of the $\mathrm{Si}-\mathrm{H}$ bond by the borane. $\mathrm{Cl}^{-}$is used as a co-catalyst in the $\mathrm{CO}_{2}$ epoxide copolymerization process and the NMR scale trial reaction was performed in the absence of $\mathrm{PPNCl}$. The successful one-pot reaction was confirmed with ${ }^{1} \mathrm{H},{ }^{13} \mathrm{C}$, HSQC and refocused INEPT ${ }^{29} \mathrm{Si}$ NMR spectroscopy (Fig. S1-S6†), and integration of ${ }^{1} \mathrm{H}$ NMR signals for the residual vinyl protons and the silyl protons $\left(\mathrm{Si}-\left(\mathrm{CH}_{3}\right)_{2}, \mathrm{Si}-\mathrm{ArH}\right)$ showed $10 \%$ of the vinyl groups

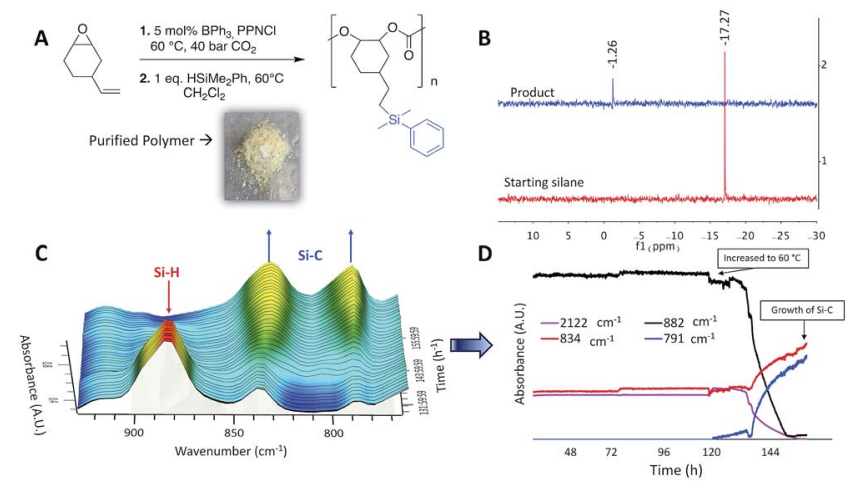

Fig. 1 One-pot assisted tandem catalysis to yield silane modified polycarbonates. (A) One-pot catalytic formation of silylated-PVCHC. (B) Refocused INEPT ${ }^{29} \mathrm{Si} N M R$ spectra of $\mathrm{PhMe}_{2} \mathrm{SiH}$ and product. (C) In situ IR spectra of reaction mixture over time. (D) Reaction profile obtained from in situ IR data. had been modified. In the refocused INEPT ${ }^{29} \mathrm{Si}$ NMR spectrum of the product, a new signal appeared at $\delta=-1.26 \mathrm{ppm}$ characteristic of a Si-C saturated bond $c f$. $\mathrm{PhMe}_{2} \mathrm{SiH} \delta=$ -17.27 ppm. Gel permeation chromatography (GPC) traces show an increase in $M_{\mathrm{n}}$ for the product, while calculated MarkHouwink-Sakurada (MHS) confirmation plots show an increased degree of branching in the product $(a=0.697$ in PVCHC vs. silyl-PVCHC $a=0.479$ ), further confirming successful functionalization (Fig. S7 and S8†). ${ }^{32}$ As anticipated the silyl-modified polymer exhibited a lower glass transition temperature $\left(T_{\mathrm{g}}\right) 71.5{ }^{\circ} \mathrm{C}$ compared with PVCHC, 99.0 ${ }^{\circ} \mathrm{C}$. This $T_{\mathrm{g}}$ may possibly be further decreased if a larger proportion of vinyl groups are converted or a different silane employed. Polycarbonates with relatively low $T_{\mathrm{g}}$ includes commercially available polypropylene carbonate that finds applications in films and coatings. This one-pot copolymerization-silylation process is an example of assisted tandem catalysis, ${ }^{33}$ as the silane reagent triggers the mode of catalysis to change, and represents a new approach to functionalized polycarbonate.

To obtain more examples of functional polycarbonates, while building upon past examples of mixed epoxide $/ \mathrm{CO}_{2}$ terpolymerizations, ${ }^{\mathbf{3 4 - 3 8}}$ we sought to investigate our $\mathrm{BPh}_{3} / \mathrm{PPNCl}$ catalytic system for similar activity. In our previous research, when propylene oxide (PO) was used as the substrate neither polypropylene oxide nor polypropylene carbonate (PPC) was formed. ${ }^{18}$ However, when an initial monomer mixture of $50: 50$ CHO : PO was used, we saw an incorporation ratio of $4: 1$ $\mathrm{CHO}$ : $\mathrm{PO}$ in the resulting polycarbonate i.e. 20\% PPC linkages (Table 1, entry 1). Moving to a 10:90 CHO : PO monomer mixture, a terpolymer with 50\% PPC linkages and a lower $T_{\mathrm{g}}$, $37.3{ }^{\circ} \mathrm{C}$, was obtained (Table 1, entry 2). From in situ IR monitoring, in addition to terpolymer, a notable amount of cyclic propylene carbonate formed. However, traces showed from a kinetic standpoint while the cyclic product formed quickly, once polymerization began there was no further cyclic formation (Fig. S13†). Instead the starting PO monomer continued to insert into the growing polymeric chain. When these ratios were reversed 90 : $10 \mathrm{CHO}$ : PO (Table 1 , entry 3), the polymer contained mostly PCHC linkages with a $T_{\mathrm{g}}$ similar to polycyclohexene carbonate. When $\mathrm{CHO}$ was replaced with VCHO in combination with PO (Table 1, entries 1 and 4), a larger proportion of PO was incorporated into the terpolymer. The $\mathrm{BPh}_{3} / \mathrm{PPNCl}$ system did not give cyclic or polymer product when glycidol was used (Table 1, entry 6). Allyl glycidyl ether (AGE) in the presence of CHO or VCHO (Table 1, entries 7 and 9) could be incorporated into terpolymers but only modest amounts of AGE were found in the resulting polymer. All obtained terpolymers were characterized by ${ }^{1} \mathrm{H}$ and ${ }^{13} \mathrm{C}$ NMR spectroscopy, GPC and DSC (Fig. S9-S26†). DOSY NMR spectroscopy confirmed the incorporation of both epoxides within the same polymeric chain. The terpolymers with alkene functionality (i.e. those containing VCHO and AGE) are attractive as they introduce the potential to further modify the polymers.

Building upon our initial polycarbonate hydrosilylation results, we then performed 'one-pot' hydrosilylation using the CHO/VCHO terpolymer (Table 1, entry 8) following similar procedures to those discussed above (Fig. 2). For the 
Table 1 Tepolymerizations of epoxides and $\mathrm{CO}_{2}$ catalyzed by $\mathrm{BPh}_{3}{ }^{a}$

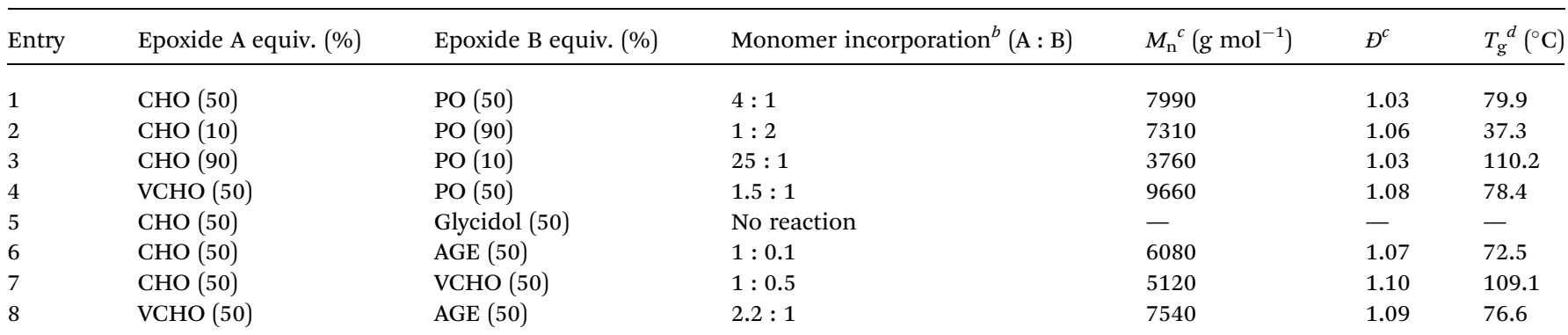

${ }^{a}$ General reaction conditions unless otherwise indicated: total epoxide (A + B) (0.025 mol), $\mathrm{PPNCl}(0.124 \mathrm{mmol}), \mathrm{BPh}_{3}(0.124 \mathrm{mmol}), 60{ }^{\circ} \mathrm{C}, 40 \mathrm{bar}$ $\mathrm{CO}_{2}$. All obtained terpolymers contained $>99 \% \mathrm{CO}_{3}$ linkages, no evidence of polyether formation. ${ }^{b}$ Determined by ${ }^{1} \mathrm{H}$ NMR spectroscopy. ${ }^{c} D$, dispersity $=M_{\mathrm{w}} / M_{\mathrm{n}}$. Determined in THF by GPC equipped with a multiangle light-scattering detector. ${ }^{d}$ Determined from DSC.

copolymerization step, a catalyst loading of $2.5 \mathrm{~mol} \% \mathrm{BPh}_{3}$ was used, which corresponds to $5 \mathrm{~mol}^{\mathrm{O}} \mathrm{BPh}_{3}$ for the hydrosilylation step (as only 50\% VCHO was present). After $24 \mathrm{~h}$ the vessel was cooled, depressurized and a mixture of diphenylsilane in dichloromethane was injected into the vessel. The mixture was then heated to $60{ }^{\circ} \mathrm{C}$ for $24 \mathrm{~h}$. Via in situ IR spectroscopy, we observed a decreased in intensity of the silane bands (2144 and $845 \mathrm{~cm}^{-1}$ ), which plateaued after approx. $12 \mathrm{~h}$ and growth of a band at $830 \mathrm{~cm}^{-1}$ corresponding to the hydrosilylated product. The hydrosilylated polymer was further characterized by ${ }^{1} \mathrm{H},{ }^{13} \mathrm{C}$, HSQC and refocused INEPT ${ }^{29} \mathrm{Si}$ NMR spectroscopy (Fig. S27-S32 $\dagger$ ). From ${ }^{1} \mathrm{H}$ NMR integration of signals for the residual vinyl protons and the aromatic protons $\left(-\mathrm{SiPh}_{2}\right), 36 \%$ of vinyl groups had been modified. The refocused INEPT ${ }^{29} \mathrm{Si}$ NMR spectrum of the product had a resonance at $\delta=$ -19.32 ppm, $c f . \delta=-33.18 \mathrm{ppm}\left(\mathrm{Ph}_{2} \mathrm{SiH}_{2}\right)$. From both ${ }^{1} \mathrm{H}$ and refocused INEPT ${ }^{29} \mathrm{Si}$ NMR it is evident that only one $\mathrm{Si}-\mathrm{H}$ bond added across the alkene of the terpolymer and hence no crosslinking occurred. From DSC data, a decline in $T_{\mathrm{g}}$ from $111.6{ }^{\circ} \mathrm{C}$ to $47.8{ }^{\circ} \mathrm{C}$ was observed for the silylated product (Fig. S33 ${ }^{\dagger}$ ). From GPC, an increase in molecular weight from $4.31 \times 10^{3} \mathrm{~g}$ $\mathrm{mol}^{-1}(\nexists=1.07)$ to $6.20 \times 10^{3} \mathrm{~g} \mathrm{~mol}^{-1}(\nexists=1.12)$ was observed as well as increased branching in MHS confirmation plots (Fig. S34†).

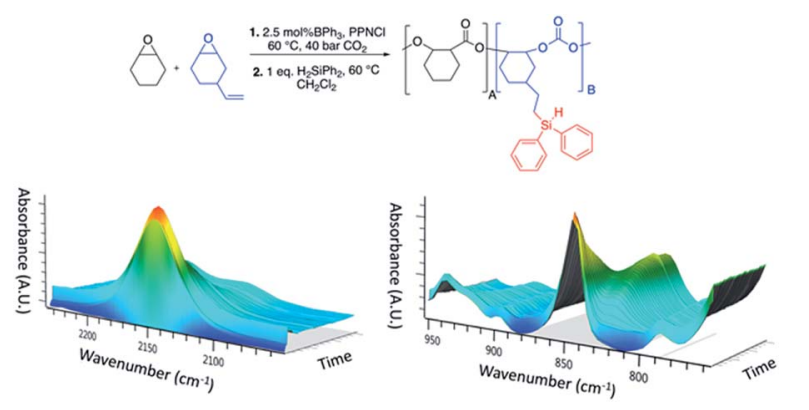

Fig. 2 One-pot assisted tandem catalysis to yield silylated-terpolymers. General reaction scheme (top) and three-dimensional plots obtained via in situ IR spectroscopy showing a decreased for silane bands and growth of product bands (bottom).
Finally, we set out to evaluate the substrate scope of these transformations by evaluating the reactivity of a hydride terminated polydimethylsiloxane. For the hydride terminated polydimethylsiloxane (DMS-HO3) and PVCHC, the resulting polymer was characterized by ${ }^{1} \mathrm{H},{ }^{13} \mathrm{C}$, refocused INEPT ${ }^{29} \mathrm{Si}$, and H-Si HMQC NMR spectroscopy (Fig. S35$\mathrm{S} 37 \dagger)$. Via integration of the ${ }^{1} \mathrm{H}$ NMR spectrum, hydrosilylation has occurred to a similar extent to other hydrosilylations reported herein. We note that only one $\mathrm{Si}-\mathrm{H}$ group per DMS-HO3 has undergone reaction and no cross-linking between polycarbonate chains was indicated by NMR and DSC data. IR spectra of the hydrosilylated-polycarbonate showed new bands at $\nu=1013,907$ and $788 \mathrm{~cm}^{-1}$ corresponding to $\mathrm{O}-\mathrm{Si}-\mathrm{O}, \mathrm{Si}-\mathrm{H}$ and $\mathrm{Si}-\mathrm{CH}_{3}$ groups respectively (Fig. S38†). From GPC, there was a moderate increase in molecular weight and no significant change in $D$. There was a decline in the slope of the MHS plot indicating a higher degree of branching in the final product (Fig. S39†). DSC analysis demonstrated a slight increase in $T_{\mathrm{g}}$ from $99.0^{\circ} \mathrm{C}$ to 104.6 ${ }^{\circ} \mathrm{C}$. The residual unreacted $\mathrm{Si}-\mathrm{H}$ bonds in the functionalized polymer introduces further functionality potential. For example, BCF has been reported to catalyze the addition of $\mathrm{Si}-\mathrm{H}$ bonds onto silica derived materials. ${ }^{39}$

In summary, we report the first example of $\mathrm{BPh}_{3}$ catalyzed hydrosilylation of perfectly alternating PVCHC in a tandem catalytic manner. These reactions were monitored by in situ IR spectroscopy, which demonstrated the addition of the $\mathrm{Si}-\mathrm{H}$ bond across the pendent alkenes in the polymer. In an attempt to build new classes of polymeric materials, we showed the ability of $\mathrm{BPh}_{3}$ to catalyze the terpolymerization of $\mathrm{CO}_{2}$ and several epoxide combinations, yielding products with $T_{\mathrm{g}}$ values from $37.3{ }^{\circ} \mathrm{C}$ to $110.2{ }^{\circ} \mathrm{C}$, which we could then functionalize in a similar one-pot manner as above. Finally, we evaluated the reactivity of a polymeric hydride terminated siloxane which can serve as a precursor for silica surface modification. Using the results in-hand, we will work towards developing sustainable surface functionalized materials in the future. 


\section{Conflicts of interest}

There are no conflicts to declare.

\section{Acknowledgements}

The authors thank Dr Celine Schneider (Memorial University) for assistance and discussions regarding NMR studies. NSERC of Canada, Memorial University, CFI and RDC-NL are thanked for operating and infrastructure grants. K. A. A is supported by a Vanier Canada Graduate Scholarship.

\section{Notes and references}

1 J. Artz, T. E. Müller, K. Thenert, J. Kleinekorte, R. Meys, A. Sternberg, A. Bardow and W. Leitner, Sustainable Conversion of Carbon Dioxide: An Integrated Review of Catalysis and Life Cycle Assessment, Chem. Rev., 2018, 118, 434-504.

2 M. Aresta, A. Dibenedetto and A. Angelini, Catalysis for the Valorization of Exhaust Carbon: from $\mathrm{CO}_{2}$ to Chemicals, Materials, and Fuels. Technological Use of $\mathrm{CO}_{2}$, Chem. Rev., 2014, 114, 1709-1742.

3 M. Cokoja, C. Bruckmeier, B. Rieger, W. A. Herrmann and F. E. Kühn, Transformation of Carbon Dioxide with Homogeneous Transition-Metal Catalysts: A Molecular Solution to a Global Challenge?, Angew. Chem., Int. Ed., 2011, 50, 8510-8537.

4 Q. Liu, L. Wu, R. Jackstell and M. Beller, Using Carbon Dioxide as a Building Block in Organic Synthesis, Nat. Commun., 2015, 6, 5933.

$5 \mathrm{M}$. North and P. Styring, Perspectives and Visions on $\mathrm{CO}_{2}$ Capture and Utilisation, Faraday Discuss., 2015, 183, 489502.

6 G. Trott, P. K. Saini and C. K. Williams, Catalysts For $\mathrm{CO}_{2} /$ epoxide Ring-opening Copolymerization, Philos. Trans. $R$. Soc., A, 2016, 374, 20150085.

7 O. Hauenstein, S. Agarwal and A. Greiner, Bio-based Polycarbonate as Synthetic Toolbox, Nat. Commun., 2016, 7, 11862.

8 Y. Wang and D. J. Darensbourg, Carbon Dioxide-based Functional Polycarbonates: Metal Catalyzed Copolymerization of $\mathrm{CO}_{2}$ and Epoxides, Coord. Chem. Rev., 2018, 372, 85-100.

9 S. Liu, X. Zhao, H. Guo, Y. Qin, X. Wang and F. Wang, Construction of Well-Defined Redox-Responsive $\mathrm{CO}_{2}$-Based Polycarbonates: Combination of Immortal Copolymerization and Prereaction Approach, Macromol. Rapid Commun., 2017, 38, 1600754.

10 A. E. Cherian, F. C. Sun, S. S. Sheiko and G. W. Coates, Formation of Nanoparticles by Intramolecular CrossLinking: Following the Reaction Progress of Single Polymer Chains by Atomic Force Microscopy, J. Am. Chem. Soc., 2007, 129, 11350-11351.

11 D. J. Darensbourg, W.-C. Chung, C. J. Arp, F.-T. Tsai and S. J. Kyran, Copolymerization and Cycloaddition Products Derived from Coupling Reactions of 1,2-Epoxy-4- cyclohexene and Carbon Dioxide. Postpolymerization Functionalization via Thiol-Ene Click Reactions, Macromolecules, 2014, 47, 7347-7353.

12 G.-W. Yang, Y.-Y. Zhang, Y. Wang, G.-P. Wu, Z.-K. Xu and D. J. Darensbourg, Construction of Autonomic Self-Healing $\mathrm{CO}_{2}$-Based Polycarbonates via One-Pot Tandem Synthetic Strategy, Macromolecules, 2018, 51, 1308-1313.

13 C. Martín and A. W. Kleij, Terpolymers Derived from Limonene Oxide and Carbon Dioxide: Access to CrossLinked Polycarbonates with Improved Thermal Properties, Macromolecules, 2016, 49, 6285-6295.

14 T. Stößer, C. Li, J. Unruangsri, P. K. Saini, R. J. Sablong, M. A. R. Meier, C. K. Williams and C. Koning, Bio-derived Polymers for Coating Applications: Comparing Poly(Limonene Carbonate) and Poly(Cyclohexadiene Carbonate), Polym. Chem., 2017, 8, 6099-6105.

15 C. M. Kozak, K. Ambrose and T. S. Anderson, Copolymerization of Carbon Dioxide and Epoxides by Metal Coordination Complexes, Coord. Chem. Rev., 2018, 376, 565-587.

16 R. R. Shaikh, S. Pornpraprom and V. D'Elia, Catalytic Strategies for the Cycloaddition of Pure, Diluted, and Waste $\mathrm{CO}_{2}$ to Epoxides under Ambient Conditions, ACS Catal., 2018, 8, 419-450.

17 D. Zhang, S. K. Boopathi, N. Hadjichristidis, Y. Gnanou and X. Feng, Metal-Free Alternating Copolymerization of $\mathrm{CO}_{2}$ with Epoxides: Fulfilling "Green" Synthesis and Activity, $J$. Am. Chem. Soc., 2016, 138, 11117-11120.

18 K. A. Andrea and F. M. Kerton, Triarylborane-Catalyzed Formation of Cyclic Organic Carbonates and Polycarbonates, ACS Catal., 2019, 9, 1799-1809.

19 D. W. Stephan, The Broadening Reach of Frustrated Lewis Pair Chemistry, Science, 2016, 354, aaf7229.

20 J. R. Lawson and R. L. Melen, Tris(pentafluorophenyl)borane and Beyond: Modern Advances in Borylation Chemistry, Inorg. Chem., 2017, 56, 8627-8643.

21 M. Rubin, T. Schwier and V. Gevorgyan, Highly efficient $\mathrm{B}\left(\mathrm{C}_{6} \mathrm{~F}_{5}\right)_{3}$-catalyzed hydrosilylation of olefins, J. Org. Chem., 2002, 67, 1936-1940.

22 M. Pérez, L. J. Hounjet, C. B. Caputo, R. Dobrovetsky and D. W. Stephan, Olefin Isomerization and Hydrosilylation Catalysis by Lewis Acidic Organofluorophosphonium Salts, J. Am. Chem. Soc., 2013, 135, 18308-18310.

23 M. H. Holthausen, M. Mehta and D. W. Stephan, The Highly Lewis Acidic Dicationic Phosphonium Salt: [(SIMes) $\mathrm{PFPh}_{2}$ ] $\left[\mathrm{B}\left(\mathrm{C}_{6} \mathrm{~F}_{5}\right)_{4}\right]_{2}$, Angew. Chem., Int. Ed., 2014, 53, 6538-6541.

24 A. Simonneau and M. Oestreich, 3-Silylated Cyclohexa-1,4dienes as Precursors for Gaseous Hydrosilanes: The $\mathrm{B}\left(\mathrm{C}_{6} \mathrm{~F}_{5}\right)_{3}$-Catalyzed Transfer Hydrosilylation of Alkenes, Angew. Chem., Int. Ed., 2013, 52, 11905-11907.

25 M. Oestreich, Transfer Hydrosilylation, Angew. Chem., Int. Ed., 2016, 55, 494-499.

26 X. Zeng, Recent Advances in Catalytic Sequential Reactions Involving Hydroelement Addition to Carbon-Carbon Multiple Bonds, Chem. Rev., 2013, 113, 6864-6900. 
27 Y. Nakajima and S. Shimada, Hydrosilylation Reaction of Olefins: Recent Advances And Perspectives, RSC Adv., 2015, 5, 20603-20616.

28 D. J. Darensbourg and Y. Wang, Terpolymerization of Propylene Oxide and Vinyl Oxides With $\mathrm{CO}_{2}$ : Copolymer Cross-Linking and Surface Modification via Thiol-Ene Click Chemistry, Polym. Chem., 2015, 6, 1768-1776.

29 A. Berkefeld, W. E. Piers and M. Parvez, Tandem Frustrated Lewis Pair/Tris(Pentafluorophenyl)Borane-Catalyzed Deoxygenative Hydrosilylation of Carbon Dioxide, J. Am. Chem. Soc., 2010, 132, 10660-10661.

30 L. C. Wilkins, J. L. Howard, S. Burger, L. Frentzel-Beyme, D. L. Browne and R. L. Melen, Exploring Multistep Continuous-Flow Hydrosilylation Reactions Catalyzed by Tris(Pentafluorophenyl)Borane, Adv. Synth. Catal., 2017, 359, 2580-2584.

31 D. Mukherjee, D. F. Sauer, A. Zanardi and J. Okuda, Selective Metal-Free Hydrosilylation of $\mathrm{CO}_{2}$ Catalyzed by Triphenylborane in Highly Polar, Aprotic Solvents, Chem.Eur. J., 2016, 22, 7730-7733.

32 S. Mori and H. G. Barth, Size Exclusion Chromatography, Springer-Verlag, Berlin-Heidelberg-New York, 1999.

33 D. E. Fogg and E. N. dos Santos, Tandem Catalysis: A Taxonomy and Illustrative Review, Coord. Chem. Rev., 2004, 248, 2365-2379.
$34 \mathrm{H}$. Li and Y. Niu, Alternating Copolymerization of $\mathrm{CO}_{2}$ with Propylene Oxide and Terpolymerization with Aliphatic Epoxides by Bifunctional Cobalt Salen Complex, Polym. J., 2010, 43, 121-125.

35 J. E. Seong, S. J. Na, A. Cyriac, B. W. Kim and B. Y. Lee, Terpolymerizations of $\mathrm{CO}_{2}$, Propylene Oxide, and Various Epoxides Using a Cobalt(III) Complex of Salen-Type Ligand Tethered by Four Quaternary Ammonium Salts, Macromolecules, 2010, 43, 903-908.

36 G. P. Wu, P. X. Xu, Y. P. Zu, W. M. Ren and X. B. Lu, Cobalt(III)-Complex-Mediated Terpolymerization of $\mathrm{CO}_{2}$, Styrene Oxide, and Epoxides with an Electron-Donating Group, J. Polym. Sci., Part A: Polym. Chem., 2013, 51, 874-879.

37 D. J. Darensbourg, R. R. Poland and A. L. Strickland, (Salan) $\mathrm{CrCl}$, An Effective Catalyst for the Copolymerization and Terpolymerization of Epoxides and Carbon Dioxide, $J$. Polym. Sci., Part A: Polym. Chem., 2012, 50, 127-133.

38 K. Deng, S. Wang, S. Ren, D. Han, M. Xiao and Y. Meng, A Novel Single-Ion-Conducting Polymer Electrolyte Derived from $\mathrm{CO}_{2}$-Based Multifunctional Polycarbonate, ACS Appl. Mater. Interfaces, 2016, 8, 33642-33648.

39 N. Moitra, S. Ichii, T. Kamei, K. Kanamori, Y. Zhu, K. Takeda, K. Nakanishi and T. Shimada, Surface Functionalization of Silica by Si-H Activation of Hydrosilanes, J. Am. Chem. Soc., 2014, 136, 11570-11573. 